\title{
CARON, Anita, collectif sous la direction de, Femmes et pouvoir dans l'Église. Montréal, VLB éditeur, 1991. 256 p.
}

\section{Monique Hamelin}

Volume 46, numéro 3, hiver 1993

URI : https://id.erudit.org/iderudit/305116ar

DOI : https://doi.org/10.7202/305116ar

Aller au sommaire du numéro

Éditeur(s)

Institut d'histoire de l'Amérique française

ISSN

0035-2357 (imprimé)

1492-1383 (numérique)

Découvrir la revue

Citer ce compte rendu

Hamelin, M. (1993). Compte rendu de [CARON, Anita, collectif sous la direction de, Femmes et pouvoir dans l'Église. Montréal, VLB éditeur, 1991. 256 p.] Revue d'histoire de l'Amérique française, 46(3), 510-512.

https://doi.org/10.7202/305116ar d'utilisation que vous pouvez consulter en ligne.

https://apropos.erudit.org/fr/usagers/politique-dutilisation/ 
CARON, Anita, collectif sous la direction de, Femmes et pouvoir dans l'Église. Montréal, VLB éditeur, 1991. 256 p.

«... l’Église est une institution féminine ou une institution de femmes, organisée et dirigée par des hommes.» (p. 37)

Ces mots de Nicole Laurin-Frenette et Nadia Fahmy-Eid résument assez bien la place des femmes dans l'Église catholique. Alors que cette dernière continue «sa politique de ségrégation des sexes» (p. 241), alors que les femmes sont toujours exclues de l'appareil ecclésial, une équipe de chercheures, sous la direction d'Anita Caron, a voulu cerner cette question de l'accès des femmes à des fonctions hiérarchiques, à travers l'expérience vécue en paroisse. 
La période choisie couvre les années $1945-1985$ et le terrain d'analyse se situe au Québec, plus particulièrement sur l'île de Montréal. Les données sont multiples et tirées de plusieurs sources: archives de deux paroisses, entrevues d'une vingtaine de femmes actives dans l'une ou l'autre de ces paroisses et dans l'une ou l'autre des associations pieuses ou charitables, des mouvements d'action catholique, des organismes familiaux, des groupes d'entraide ou apostoliques, entrevues aussi avec les responsables actuels et les ex-pasteurs de ces communautés et quelques hommes laïques qui ont collaboré avec des femmes de ces paroisses. Enfin, on examine d'une part l'impact de deux groupes féministes et chrétiens sur la reconnaissance du statut des femmes dans l'Église, et d'autre part la question de l'insertion des femmes dans les structures du Diaconat permanent.

Ce travail en collectif a permis à dix chercheures (sociologues, historiennes et spécialistes des sciences religieuses) de poser un regard complémentaire sur une organisation qui, si elle n'a plus l'ascendant des années quarante, reste quand même influente. En effet, comme le rappelle MarieAndrée Roy, «L'Église catholique, par son discours et sa pratique, contribue à légitimer le sexisme des sociétés occidentales à l'endroit des femmes» (p. 241).

L'étude des données montre qu'il y a eu changements et même une certaine évolution. Évolution il y a eu si l'on examine les périodes 1945-1960 et 1975-1985. Dans le premier cas, les femmes œuvrent dans des associations non mixtes. Il en va tout autrement pour les années 1975-1985, car sauf pour la popote roulante dans l'une des paroisses il n'y a plus rien de spécifiquement féminin. C'est au cours des années soixante, comme le souligne Flore Dupriez, que l'on voit naître «un large mouvement d'émancipation face à la tutelle des clercs» (p. 31). Quoique, comme le notent les auteures Caron, Lafortune et Brandy pour chacune des périodes (1945-1960, 1960-1975, 1975-1985), même si les femmes sont toujours très présentes, il n'est pas possible d'énoncer qu'elles ont ou ont eu du pouvoir. La description que font Campeau et Simard des groupes de femmes intra-ecclésiaux (les épouses des diacres et le mouvement des femmes chrétiennes) et d'un groupe extraecclésial (L'autre Parole) conduit à la même constatation. La marge de manœuvre des uns et des autres sera fort différente pour revendiquer l'égalité et pour s'autoriser à une prise de parole, selon les liens que l'on a ou pas avec l'institution. Dans tous les cas, ces femmes restent absentes des lieux décisionnels.

Charité, loisirs paroissiaux et bénévolat, voilà où les femmes ont une marge de manœuvre pour exercer leur pouvoir. En revanche, le responsable de la paroisse, le clerc, est beaucoup plus contrôleur lorsqu'il est question de pastorale et de liturgie. Les femmes peuvent être marguillières ou agentes de pastorale; mais malgré ces accrocs au pouvoir de domination, qu'ils soient légalistes (des femmes animatrices de pastorale signent les registres) ou non traditionnels (on retrouve de plus en plus de femmes agentes de pastorales), le clerc reste le leader charismatique, tout lui est subordonné. L'ouverture n'est pas consignée dans le droit canon, les dérogations sont à la pièce, l'ouverture est réversible. Marie-Andrée Roy pose ce constat en ulitisant un 
modèle wébérien d'analyse (p. 143 et ss). Les chapitres de Lafortune et Roy sur les rapports sociaux de sexes selon le modèle de Christine Delphy, et sur le sexage d'après la théorie de Colette Guillaumin, présentent une lecture nouvelle et fort intéressante de la position de subordination des femmes dans l'Église, et de l'appropriation des femmes par les hommes et par les clercs en particulier.

En outre, Nusia Matura nous donne une synthèse des positions des trois grandes théologiennes américaines de tradition catholique que sont Mary Daly, Rosemary Radford Ruether et Elisabeth Schüssler-Fiorenza. Elle termine ce chapitre en soulignant les points de convergences entre la pensée de ces théologiennes et celle des femmes interviewées.

Si les femmes sont si présentes au service de l'Église, c'est que leurs actions en paroisse présentent un «important lieu de réalisation personnelle», de valorisation, d'acquisition d'un comportement autonome. Elles rompent aussi avec la solitude et elles s'émancipent du foyer. Il ne faudrait pas non plus négliger que pour plusieurs c'est une expérience de croissance morale et spirituelle (p. 128-129).

Néanmoins, à travers les témoignages de ces femmes qui œuvrent en paroisse nous sentons leur lucidité devant «l'égalité inexistante», inégalité qu'elles déplorent sans toutefois l'exprimer en terme de discrimination. Pour continuer, elles misent sur les relations interpersonnelles. Mais l'Église catholique est partie prenante de l'ordre patriarcal dans notre société, et de ce fait les choses ne sont pas prêtes de changer tant que les femmes ne s'organiseront pas entre elles, concluent les auteures.

Cet ouvrage, qui s'est d'ailleurs valu le Prix Edgar-Lespérance (1991), propose une nouvelle lecture de la place des femmes dans l'Église catholique, plus spécifiquement au palier paroissial. De par la diversité de leur champ disciplinaire, la qualité de leur écriture, le choix d'une grille d'analyse résolument féministe et leur souci de lier de façon serrée les données qualitatives au modèle théorique choisi, les auteures permettent de faire une avancée certaine dans la compréhension du pouvoir d'une organisation si résolument sexiste. 